ORIGINAL

\title{
Asociación entre receptores de leptina en testículo, niveles de leptina y testosterona en terneros púberes
}

\section{Association between leptin receptors in the testicle, leptin and testosterone levels in puber male calves}

\author{
Z.Tatiana Ruiz-Cortés, ${ }^{1 *}$ Ph.D, Martha Olivera A, ${ }^{1}$ Dr.Sc. \\ ${ }^{1}$ Universidad de Antioquia, Facultad de Ciencias Agrarias, Grupo de Investigación Biogénesis, Robledo, \\ Medellín, Colombia. *Correspondencia: ztatiana@agronica.udea.edu.co
}

Recibido: Agosto 10 de 2009; Aceptado: Junio 18 de 2010.

\section{RESUMEN}

Objetivos. Describir la presencia de receptores de leptina (OBR) en el testículo en la llegada de la pubertad en terneros y estudiar la posible asociación entre la expresión de éstos y los niveles de leptina (L) y de testosterona. Materiales y métodos. Se utilizaron 6 terneros Holstein x Cebú a los cuales se les midió quincenalmente y durante 7 meses concentraciones de testosterona y de L por RIA. Fueron castrados unilateralmente según períodos peripuberales para estudiar por RT-PCR la expresión de isoformas del receptor de L. El análisis estadístico se realizó con el programa Statistica ${ }^{\circledR}$. Resultados. La testosterona presentó niveles desde menores a $1 \mathrm{ng} / \mathrm{mL}$ a los 6 y 6.5 meses de edad, hasta concentraciones de $5.3 \mathrm{ng} / \mathrm{ml}$ a los 12.5 meses antes de la llegada a pubertad, momento en el cual los animales tuvieron niveles de $4.01 \pm 1.8 \mathrm{ng} / \mathrm{ml}$. Las concentraciones de $\mathrm{L}$ variaron entre 0.61 y $0.98 \mathrm{ng} / \mathrm{ml}$, con una concentración en pubertad de $0.91 \pm 0.05 \mathrm{ng} / \mathrm{ml}$. Dos isoformas, OBRi y OBRb, fueron encontradas y se correlacionaron significativamente entre ellas en la pubertad. Se hallaron correlaciones negativas entre OBRi-OBRb y niveles de testosterona y de $L(p=0.08)$. Los niveles de testosterona y de $L$ mostraron una correlación directa significativa. Conclusiones. Se sugiere un posible efecto directo de la leptina en gónadas de terneros hasta la llegada a pubertad. La correlación entre las isoformas de OBR y su asociación con las concentraciones de leptina y testosterona también sugiere la acción complementaria o conjunta de ambos receptores OBR en testículos de terneros peripuberales.

Palabras clave: Gen obesidad, hormonas, maduración sexual machos. 


\section{ABSTRACT}

Objectives. To describe the presence of leptin receptors (ObR) in the testicle during puberty in calves and study the possible association between the expression of the testicles and the levels of leptin (L) and testosterone. Materials and methods. During 7 months every two weeks on six Holstein $x$ Zebu calves, concentrations of testosterone and $L$ were measured by RIA. They were castrated unilaterally according to their peribubertal periods in order to study by RT-PCR the expression of the $L$ receptor isoforms. The statistical analysis was done with the Statistica $\cap$ program. Results. The levels of testosterone were $<1 \mathrm{ng} / \mathrm{mL}$ at 6 and 6.5 months of age, concentrations of $5.3 \mathrm{ng} / \mathrm{ml}$ at 12.5 months were reached before puberty, moment in which the animals had levels of $4.01 \pm 1.8 \mathrm{ng} / \mathrm{ml}$. The $\mathrm{L}$ concentrations varied between 0.61 and $0.98 \mathrm{ng} / \mathrm{ml}$, with a concentration at puberty of $0.91 \pm 0.05 \mathrm{ng} / \mathrm{ml}$. Two isoforms, OBRi and OBRb, were found and correlated significantly at puberty. Negative correlations were found between OBRi-OBRb and the testosterone and $L(p=0.08)$ levels. Testosterone and $L$ levels showed a significant direct correlation. Conclusions. A possible direct effect of leptin on calf gonads until they reach puberty is suggested. The correlation between the OBR isoforms and their association to leptin and testosterone concentrations also suggests the complimentary or joint action of both OBR receptors in peripubertal calves' gonads.

key words: Obesity gene, hormone, male sexual maturation

\section{INTRODUCCIÓN}

La leptina es una hormona proteínica de 16 $\mathrm{KDa}$, está compuesta por 146 aminoácidos y es sintetizada principalmente por el tejido adiposo. Esta hormona es codificada por el gen $o b$, identificado originalmente en estudios conducentes a identificar las causas de la obesidad en el ratón obeso (ob/ob) (1). La leptina actúa a través de receptores específicos de membrana (OBR) los que se han demostrado como altamente similares con los receptores de la familia interleuquina 6 (IL-6) (2-5). Las isoformas de receptores de leptina, incluyen receptores de forma larga (OBRb) y varios receptores de forma corta (OBRa, OBRc, OBRd y OBRf), así como el receptor soluble (OBRe) que se encuentra en plasma circulante $(5,6)$.

La proteína o el ARNm de receptores de leptina han sido encontrados en gran variedad de tejidos incluyendo tejido adiposo blanco y pardo, páncreas, intestino, hígado, músculo esquelético, placenta, cerebro, glándula mamaria, corteza adrenal, en el ovario en células de la granulosa, células de la teca y en cuerpo lúteo y en testículo, en espermatocitos y en células de Leydig $(2,7-11)$.
En el eje hipotálamo-hipófisis-gonadal, la leptina juega un papel muy importante en la regulación de la reproducción de los mamíferos. Actúa en la regulación y secreción de la hormona liberadora de gonadotropinas (GnRH) por el hipotálamo $(12,13)$ y en la hipófisis modula la secreción de la hormona luteinizante (LH), como sucede en algunas especies animales tales como, cerdos $(4,14)$, primates (15), roedores (16), oveja (17) y bovinos (12).

En las hembras bovinas, la leptina está relacionada con la regulación del ciclo estral y probablemente está involucrada en el control de la reproducción. Según Williams et al (12), la leptina circulante disminuye durante la fase luteal y folicular del ciclo estral, en vacas y novillas sexualmente maduras, variación concomitante con la variación en las pulsaciones de LH y las concentraciones séricas de insulina e IGF-1 como reguladores del ciclo estral.

Además, se ha encontrado en algunos estudios, que las concentraciones sistémicas de leptina incrementan durante la pubertad en machos y hembras, tanto en humanos 
(18), como en muchas especies animales: cerdos (19), ratones (20) y ganado bovino (21). Sin embargo, el incremento sólo se mantiene en las hembras, porque en los machos los niveles de leptina disminuyen después de la pubertad (22). El modo de acción de la leptina en la reproducción en los machos ha sido muy discutido por los autores (22-25), indicando que es muy complejo por ejercer efectos tanto inhibitorios como estimulatorios del eje gonadal por ejemplo a nivel del control de la expresión de genes importantes en la vía de la esteroidogénesis (SF-1, StAR y P450scc); además, la expresión del receptor OBR muestra patrones igualmente complejos con la presencia de isoformas reguladas de manera homóloga (leptina) y heteróloga (gonadotropinas) (22), se propone que sucedería esto según el momento reproductivo del animal.

El objetivo de esta investigación fue describir la presencia de receptores de leptina (OBR) en el testículo en un modelo bovino en la llegada de la pubertad. Se hipotetiza que los OBR aumentan progresivamente su expresión en el testículo entre el periodo prepuberal y hasta el inicio de la pubertad de terneros, indicando una posible relación entre las hormonas leptina y testosterona y un efecto conjunto sobre el inicio de la pubertad.

\section{MATERIALES Y MÉTODOS}

Zona de estudio. El estudio se realizó en la ganadería Los Balcones localizada en el municipio de Santa Rosa (departamento de Antioquia-Colombia), a una altitud de 2550 metros, una temperatura promedio de $18^{\circ} \mathrm{C}$, una humedad relativa de $79 \%$ y una precipitación media anual de $2238.9 \mathrm{~mm}$, la cual la ubica en una zona de vida bmh-MB.

Animales. En el sistema de producción se seleccionaron terneros cruzados F1 (Bos taurus $x$ Bos indicus), nacidos en diferentes épocas del año por la disponiblidad de los animales. Los animales fueron alimentados desde el nacimiento hasta el destete con leche recién ordeñada (promedio de este periodo $4.5 \mathrm{It}$ ) en sistema estabulado individual, luego se llevaron a un sistema semi-estabulado con rotación de potreros a base de pasturas (Penisetum clandestinum, Lolium multiflorum y Penisetum sp) y de concentrado. Los animales fueron sometidos al plan sanitario que se realiza en el sistema de producción (desparasitación 3 veces al año, vacunas anti Aftosa y triple).

Determinación del inicio de la pubertad. Para determinar el inicio de la pubertad se tuvieron en cuenta todos los signos siguientes: la edad en meses, el peso corporal en kg, perímetro torácico en centímetros con cinta (26), la circunferencia escrotal en centímetros con cinta testicular, la observación de libido (monta a otros terneros, erección del pene, inicio de reflejo de Flehmen) todos estos parámetros medidos cada 15 días.

Además, se recolectaron muestras de orina y de líquido espermático mensualmente desde la detección de los signos de llegada a la pubertad descritos (edad, peso, perímetro testicular, libido). La muestra de orina se recolectó por masaje en el prepucio y fue centrifugada a $1800 \mathrm{~g}$ a $25^{\circ} \mathrm{C}$ y por 5 minutos, se recolectó el precipitado para posteriormente observar la presencia de espermatozoides al microscopio (Leica DME®).

Para la obtención del eyaculado se estimuló por masaje prepucial la salida de orina, se lavó la región y se procedió a utilizar un electroeyaculador (Electroyac III, Ideal Instruments $($ ) ) por un tiempo de $40-60$ segundos, con voltaje que osciló entre 12 y 20 voltios hasta la expulsión del liquido espermático. Este se observó al microscopio para determinar la presencia de al menos 50 millones de espermatozoide con al menos $10 \%$ de motilidad progresiva, con lo que se determinó finalmente que el animal estuviera en pubertad (27).

Periodos evaluados. En el experimento se evaluaron tres periodos así: a) prepuber (6-8 meses edad), b) prepuber (8-10meses de edad) verificando que estos animales no hubieran iniciado la pubertad al no presentar ninguna de las características descritas y c) inicio de la pubertad-pubertad (10m-pubertad), al presentar dichos signos. En los 2 momentos prepuber los animales 
fueron castrados unilateralmente, y en el momento $10 \mathrm{~m}$-pubertad se les castró el testículo restante. Además, se recolectaron muestras de sangre a todos los animales desde los 6 meses de edad y hasta detección de llegada a pubertad, para la evaluación de testosterona y de leptina en suero.

\section{Determinación de concentraciones} de testosterona y de leptina. En tubos secos, se recolectaron muestras quincenales de sangre $(3-5 \mathrm{ml})$ de la vena coccígea o yugular de los terneros desde los 6 meses de edad hasta la confirmación del inicio de la pubertad; la sangre se centrifugó a $1800 \mathrm{~g}$ a una temperatura de $25^{\circ} \mathrm{C}$ por 10 min en una centrífuga (IEC Centra GP8 ${ }^{\circledR}$ ) para la posterior extracción del suero y la medición de testosterona y de leptina por radioinmunoanálisis (RIA). Se envió la mitad del volumen de las muestras a la Universidad Nacional de Colombia sede Bogotá para medición de testosterona ( $T$ ) por medio de la técnica de radioinmunoanálisis (RIA) con un kit comercial DPC Coat-A Count Total Testosterone $\AA$, con sensibilidad analítica para el procedimiento básico de $1 \mathrm{ng} / \mathrm{dl}$ y coeficiente de variación inter-ensayo de aproximadamente $7 \%$ (28). La otra mitad del volumen de las muestras de suero fue sometido a liofilización y enviado a la Universidad de West Australia para su reconstitución y lectura de leptina (Lept) por la técnica de RIA descrita por otros autores $(29,30)$.

\section{Castraciones (para purificación de} ARNtotal y amplificación de ADN).

Se realizaron castraciones unilaterales por grupos; fueron preanestesiados con Xilazine ${ }^{\circledR}$ a una dosis de $0.01 \mathrm{mg} / \mathrm{kg}$ vía_intravenosa (IV) y atropina a una dosis de $0.04 \mathrm{mg} / \mathrm{kg}$ subcutánea (SC); adicionalmente, se administró anestesia local con Lidocaína $\AA 3 \mathrm{ml}$ en el cordón espermático. El postoperatorio se realizó con la aplicación de un antibiótico de amplio espectro (Penicilina-Estreptomicina) intramuscular (IM) a una dosis de 15000 $\mathrm{UI} / \mathrm{kg}$ antes del procedimiento quirúrgico. Todo el procedimiento descrito fue realizado luego de aprobación del comité de bioética de la Universidad de Antioquia (2006), siguiendo los lineamientos de la ley 84 de
1989 acerca del uso de los animales vivos en experimentos o investigaciones.

Los testículos se transportaron refrigerados $\left(4^{\circ} \mathrm{C}\right)$ en solución fosfato buffer (PBS) a $\mathrm{pH} 7.2$ y se almacenaron a $-20^{\circ} \mathrm{C}$ hasta la utilización de las técnicas que determinaron la expresión de receptores de leptina.

\section{Purificación y análisis del ARN (para RT-} PCR). El ARN total fue purificado usando un Kit de aislamiento de ARN comercial (RNeasy Fibrous Tissue - Qiagen $($ ) ; para la síntesis de la primera cadena de cADN se usaron 5 $\mu \mathrm{g}$ de $A R N$ en un volumen total de reacción de $20 \mu \mathrm{l}$ los cuales contenían Tris- $\mathrm{HCl}, \mathrm{KCl}$, $\mathrm{MgCl}_{2}, \mathrm{DTT}$, dNTPs, Transcriptasa reversa (RevertAid $^{\mathrm{TM}} \mathrm{M}$-MuLV Fermentas), y como primer se uso Oligo (dT) $)_{18}$ (Fermentas $®$ ), para confirmación de la RT-PCR el producto fue visualizado en un gel de agarosa al 1.5\% conteniendo Bromuro de Etidio $(0.7 \mu \mathrm{g} / \mathrm{mL})$.

Amplificación del ADN. Las reacciones de PCR se llevaron a cabo en un volumen total de $50 \mu \mathrm{l}$, que contenían: $3 \mu \mathrm{g} / \mathrm{mL}$ de cADN; buffer de reacción $1 \mathrm{X}(10 \mathrm{mM}$ Tris- $\mathrm{HCl} \mathrm{pH}$ 9.0; $50 \mathrm{mM} \mathrm{KCl} ; 1.1 \%$ Tritón $\left.{ }^{\circledR} \mathrm{X}-100\right) ; 1$ $\mathrm{mM}$ de $\mathrm{MgCl} 2 ; 2 \mathrm{mM}$ de cada dNTP; $0.1 \mu \mathrm{M}$ de cada primer y 1.25 Unidades de Taq DNA Polimerasa (Fermentas $®)$ ). La amplificación se efectuó en un termociclador PTC-200 (MJ Research Peltier Termal Cycler). Para la amplificación del receptor de leptina bovina (OBR) (acceso número U62385) fueron utilizados los primer: sentido (125) 5'-GTGCCAGCAACTACAGATGCTCTAC-3' y primer antisentido (356-380), '5-AGTTCATCCAGGCCTTCTGAGAACG-3' que codifican para el fragmento extracelular del receptor, sintetizados por MWG BIOTECH los cuales amplifican 2 fragmentos de 300 y 700 de pb aproximadamente (isoformas intermedia-OBRi y larga-OBRb).

Como gen de referencia se utilizó aquel que codifica para la enzima gliceraldehido 3 fosfato deshidrogenasa (GAPDH) (acceso número U85042.1) para normalizar la expresión del receptor por medio del cálculo de la relación OBR/GAPDH. Los primers de la enzima GAPDH fueron los siguientes: sentido 5'-TGCTGGTGCTGAGTATGTGGT-3' y $\quad \mathrm{primer} \quad \mathrm{a} \mathrm{n}$ is e n t ido 
5' - AGTCTTCTGGGTGG CAGTGAT- 3', sintetizados por MWG BIOTECH los cuales amplifican un fragmento de $295 \mathrm{pb}$. El perfil térmico para cada reacción consistió en una desnaturalización inicial de $94^{\circ} \mathrm{C}$ por $3 \mathrm{~min}$ seguido por 45 ciclos a $94^{\circ} \mathrm{C}$ por $1 \mathrm{~min}, 65^{\circ} \mathrm{C}$ por $1 \mathrm{~min}, 72^{\circ} \mathrm{C}$ por 2 min, terminando con una extensión final de $72^{\circ} \mathrm{C}$ por $10 \mathrm{~min}$. Los productos de la PCR fueron visualizados en geles de agarosa al $2 \%$ conteniendo Bromuro de Etidio $(0.7 \mu \mathrm{g} / \mathrm{mL})$.

Análisis estadístico. El paquete estadístico utilizado fue Statistica $(R$ para Windows 5.0, (1995) y los datos fueron presentados en promedios y desviación estándar (DE). Las variables analizadas fueron: hormonas testosterona y $\mathrm{L}$ en $\mathrm{ng} / \mathrm{ml}$ y la expresión de isoformas del receptor de leptina (OBRi, OBRb) cuantificado en unidades arbitrarias. Esto último se realizó con la normalización de los datos de expresión de las isoformas dividido en los datos de expresión del gen de referencia GAPDH, es decir obteniendo el coeficiente: expresión de isoforma numerizado/expresión de GAPDH numerizado, numerizaciones realizadas con el programa Biometra/BioDocAnalyser 2.0®.

A cada una de las variables se le verificó normalidad de distribución de datos (Shapiro Wilk's W test); las variables de expresión de receptores OBR y de niveles de $T$ fueron transformados a raíz cuadrada de los datos originales y alcanzaron normalidad; luego se realizaron análisis estadísticos descriptivos. Tras comprobación de homogeneidad de varianzas (Levene), los niveles de receptores de leptina encontrados fueron analizados por ANAVA. Las diferencias entre promedios fueron comparadas por el test de Tukey con un nivel de significancia de $(p<0.05)$. Correlaciones entre niveles de expresión de receptores y entre receptores y niveles hormonales fueron analizados por medio del coeficiente de Spearman. Un valor de $(p<0.05)$ fue considerado estadísticamente significativo.

\section{RESULTADOS}

Testosterona en período prepuber. Los niveles de testosterona presentaron niveles detectables de $1 \mathrm{ng} / \mathrm{mL}$ desde los 7.5 meses de edad con pulsos repetidos cada mes (pulsos de amplitud similar) y hasta los 11.5 meses de edad, esto es, en el período prepuber. Luego, se encontró un aumento marcado en la amplitud del pulso de testosterona con concentración máxima de $5.3 \mathrm{ng} / \mathrm{mL}, 1$ a 2 semanas antes del inicio de la pubertad, seguido de caída de los niveles hacia los 13.5 meses de edad (Figura 1).

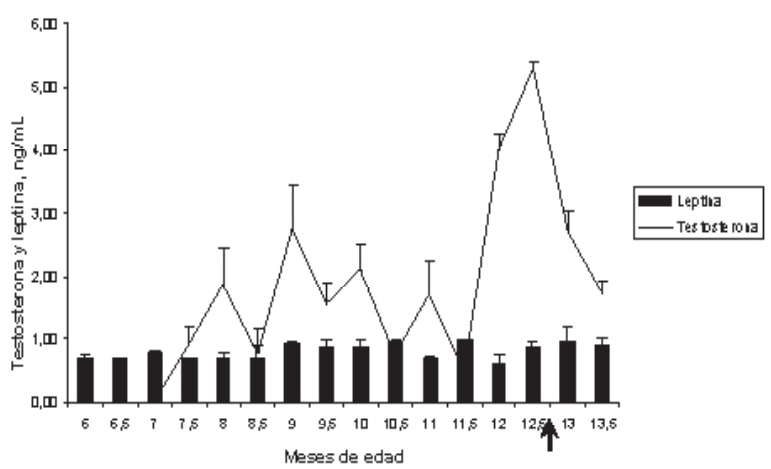

Figura 1. Niveles de testosterona y de leptina en terneros holstein $\mathrm{x}$ cebú hasta la detección de la pubertad. Promedio $\pm \mathrm{DE}$ de niveles de testosterona y de leptina en suero $(\mathrm{ng} / \mathrm{ml})$ de terneros HolsteinxCebú, desde los 6 meses de nacidos y hasta la edad promedio (12.75 \pm 1.06 meses) de la llegada a la pubertad indicada por la flecha.

Pubertad y testosterona. Cuando todos los animales estaban en un rango de edad entre 11.5 y 13.5 meses (promedio $12.75 \pm 1.06$ ), con promedio de peso de $282.8 \mathrm{Kg} \pm 45.1$, perímetro torácico de $149.5 \pm 9 \mathrm{~cm}$, circunferencia escrotal de $22.3 \pm 1.7 \mathrm{~cm}$ y niveles de testosterona de $4.01 \pm 1.2 \mathrm{ng} / \mathrm{mL}$ (Figura 1) se determinó la llegada de la pubertad. Esto se corroboró además porque los terneros mostraron reflejo de protrusión de pene (desprendimiento del prepucio) al realizarse masaje, salida de una cantidad mínima de líquido seminal con espermatozoides, y presencia de espermatozoides en orina. Se observó igualmente la monta a otros terneros, erección del pene, inicio de reflejo de Flehmen (datos no mostrados).

Niveles de leptina. Las concentraciones de $L$ no presentaron variación importante durante el período de muestreo (desde 6 
meses y hasta 13.5 meses de edad). Se encontraron dentro de un rango de $0.61 \mathrm{y}$ $0.98 \mathrm{ng} / \mathrm{mL}$ y la concentración a la pubertad fue de $0.91 \pm 0.05 \mathrm{ng} / \mathrm{mL}$.

Expresión de OBR en períodos prepuber y en pubertad. Según los oligonucleótidos o primers seleccionados, se detectaron 2 isoformas del receptor de leptina a las que se denominaron, según el peso molecular, forma larga OBRb (aprox. 700pb) y OBR intermedia (aprox. 300pb; Figura 2). La amplificación del gen GAPDH resultó en un
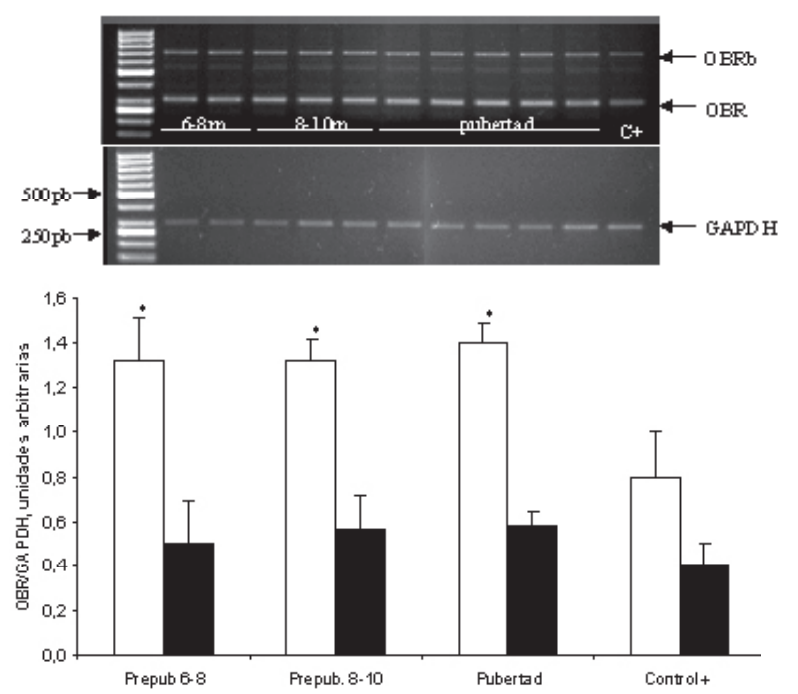

Figura 2. Cuantificación de la presencia del gen del receptor de leptina en 2 isoformas en testículos de terneros holstein $x$ cebú hasta el inicio de la pubertad. Parte superior. foto representativa de las 3 repeticiones de la técnica de RT-PCR, indicando donde se encuentran las bandas de las isoformas del gen de receptor de leptina,OBR, (aprox. 300 y $700 \mathrm{pb}$ ) y del gen GAPDH. Se ubicaron en el gel de izquierda a derecha: pozo 1. escalera, 2-3. animales de 6-8 meses de edad, 4-6. animales de 8-10 meses, 7-11. animales en pubertad, 12. Control positivo, C+: testículo bovino adulto. Parte inferior. expresión promedio $\pm \mathrm{DE}$ de 2 isoformas (larga:negro; intermedia: blanco) en testículos de terneros HolsteinxCebú en período prepuberal (6 a 8 y 8 a 10 meses de edad) y en la pubertad. Los valores de ADN amplificado fueron normalizados por el gen GAPDH. Los asteriscos indican diferencia significativa con relación al $\mathrm{C}+$. fragmento de $295 \mathrm{pb}$ claramente visible en la figura 2. Luego de realizar normalización de la carga de muestras experimentales en los geles por medio del cálculo de su coeficiente con el fragmento numerizado del gen referencia GAPDH, se encontró diferencia estadística $(p<0.05)$ entre la expresión del ADN de la isoforma OBR en las muestras de los terneros y aquella expresión en el tejido control positivo (testículo de animal adulto) se trata de una mayor expresión en las muestras de terneros en de los grupos 6-8, 8-10 y $\mathrm{P}$, comparando con dicho control (Figura 2). La isoforma OBRb, presenta un patrón similar con una mayor expresión de OBRb en las muestras experimentales comparativo al control (Figura 2) pero sin diferencia estadística $(\mathrm{p}=0.08)$.

\section{DISCUSIÓN}

\section{Niveles de testosterona}

Testosterona en período prepuber. Cambios en la secreción episódica de GnRH regula la secreción de gonadotropinas $\mathrm{LH}$ y $\mathrm{FSH}$ en terneros prepúberes lo que finalmente regula la función testicular. Ha sido ampliamente documentado desde hace más de tres décadas, que la amplitud y la frecuencia de los pulsos de LH cambian con el estado reproductivo del macho, que la secreción de LH y de testosterona es episódica y que existe una relación temporal entre estas dos hormonas en el toro (31). La liberación de LH desde las semanas 8 a 10 de edad estimula la secreción permanente de testosterona por las células de Leydig que llega a niveles máximos hacia los 10 meses de edad de los terneros (31). Más recientemente, Rawlings et al (27) describen una fase de crecimiento rápido del testículo y de glándula sexuales accesorias dependientes de andrógenos en terneros luego del mes 5 de edad y hasta el mes 12, concomitante al aumento rápido progresivo de la secreción de testosterona.

En el presente estudio se encontró que la liberación episódica de testosterona se presentó en forma de pulsos mensuales desde el mes 8 de edad y hasta el mes 12 iniciando la pubertad (Figura 1). 
Pubertad y testosterona. Los valores de edad, peso corporal, circunferencia escrotal y niveles de testosterona aqui presentados fueron anteriormente reportados hasta la pubertad para toretes venezolanos $5 / 8$ Holstein y 5/8 Pardo Suizo con 5/16 de Cebú Brahman en ambos cruces (32), es decir en cruces entre Bos taurus y Bos indicus como lo utilizado en el presente estudio. La única variable que presentó datos similares a los del presente estudio fue la de circunferencia escrotal entre 22 y $23 \mathrm{~cm}$. Es de notar que aunque la circunferencia escrotal esta referenciada como signo de llegada a pubertad que varía según las razas, se ha determinado como valor de referencia de llegada de pubertad un valor de $28 \mathrm{~cm}$, valor que sobrepasa los anteriormente mencionados (27).

Para la variable de edad a la pubertad, los animales del presente estudio parecieron ser más precoces en 2 meses comparando con Aranguren-Méndez et al (32), sumado esto a niveles de testosterona marcadamente más altos $(4.01 \mathrm{ng} / \mathrm{ml}$ en promedio vs. $1.7 \mathrm{ng} / \mathrm{ml}$ ).

Comparando con una referencia menos reciente de cruces de Bos taurus (Angus, Hereford y Pardo Suizo) (33), las concentraciones de testosterona aqui obtenidas serían relativamente bajas ya que los autores informan de rangos entre 4.3 y $7.3 \mathrm{ng} / \mathrm{ml}$ medidos ente 7 y 13 meses de edad. Por otro lado, los niveles de testosterona que se encontraron entre 1 y $5.3 \mathrm{ng} / \mathrm{mL}$ están en concordancia con lo reportado en 2007 por Brito et al (34).

Es de interés resaltar que los animales a los que les fue extraído el primer testículo a partir del mes 6 de edad, llegaron a la pubertad más rápido $(11.75 \pm 0.2)$ que aquellos con primera castración en el octavo mes (12.8 \pm 0.9$)$. Respectivamente, presentaron niveles promedio de testosterona en todo el tiempo de medición de $0.6 \pm 0.3$ y $1.6 \pm 0.5$, con menor concentración en animales castrados tempranamente. Se sugiere que se trataría de animales, que de manera compensatoria luego de la castración unilateral, son más sensibles a niveles bajos de testosterona y alcanzan pesos corporales y perímetros torácicos relacionados con el crecimiento corporal suficiente para iniciar pubertad a los 11.75 meses de edad. Sin embargo, esto es contrario a estudios de Barnes et al (35) donde terneros Holstein castrados unilateralmente mostraron de manera compensatoria incremento en el tamaño del testículo restante pero ninguna variación significativa en niveles de testosterona ni llegada a la pubertad más temprana al comparar con terneros control enteros $(35,36)$.

Niveles de leptina. Se publicó previamente (34) que terneros prepúberes AngusxCharolais, presentan niveles de leptina que aumentan constantemente desde los 6.5 meses de edad de concentraciones de $2 \mathrm{ng} / \mathrm{mL}$ hasta niveles de $5 \mathrm{ng} / \mathrm{mL}$ a los 16.5 meses de edad pasando por el período de pubertad a los 11.5 meses con $4.5 \mathrm{ng} / \mathrm{mL}$.

En el presente trabajo, la variación mínima de leptina podría verse compensada por una expresión importante de 2 isoformas de su receptor (Figura 2) como se describe en más detalle adelante. Además, es de notar que los niveles de la hormona encontrados por los autores (34), no es comparable a las bajas concentraciones descritas en el presente estudio entre 0.61 y $0.98 \mathrm{ng} / \mathrm{mL}$.

En efecto, se debe considerar la mayor frecuencia con que se realizó el muestreo y el método de medición utilizado, ya que no se usó kit multiespecie (multi-species leptin RIA kit, Linco Research, St Charles MO, USA) pero si el método específico creado en Australia (RIA) basado en leptina bovinaovina con mayor sensibilidad $(29,30)$.

\section{Expresión de OBR en períodos prepuber} y en pubertad. Estos receptores de leptina y su RNAm en testículo han sido encontrados en células de Leydig de rata $(23,37-39)$ y en equinos (40), en plasma seminal, espermatozoides $(41,42)$, y en túbulos seminíferos de humanos (42) y más recientemente en múltiples tejidos en bovinos (11). En este estudio se reporta igualmente expresión de 2 isoformas. La expresión de ambas isoformas de OBR se correlacionaron positivamente $(r=0.82$, 
$\mathrm{p}<0.01$ ) en todos los terneros, sugiriendo posibles vías de acción complementarias o conjuntas entre ellas para regular las acciones periféricas de la leptina como lo reportado recientemente en bovinos (11) y en otros sistemas (43). Los niveles de testosterona y de $\mathrm{L}$ presentan una correlación negativa con la expresión de OBRi y de OBRb $(p>0.05)$, sugiriendo que a mayores niveles de testosterona, menor expresión de los receptores de leptina en testículo.

Tena-Sempere et al (38), estudiaron el desarrollo y la regulación hormonal del RNAm del OBR en testículo de rata, planteando la posibilidad de un efecto directo de los estrógenos en testículos en desarrollo (neonatos) sobre la modulación de la expresión del gene OBR. Durante el periodo de desarrollo testicular puberal, encuentran un aumento de la expresión de receptores, como los encontrados y plantean los autores, se explicaría por el efecto de hormonas como la leptina, la hCG y la $\mathrm{FSH}$; finalmente, encuentran disminución de la expresión en animales adultos. Se propone que en este estudio también habría efecto de los niveles de testosterona en la regulación de expresión de estos receptores.

Los pocos estudios que se han realizado usando el modelo bovino, han sido en hembras y más a nivel central que local (12), en machos bovinos no se han realizado estudios que expliquen el rol de la leptina en la pubertad.

En el presente trabajo se sugieren interesantes efectos locales de la leptina relacionados con el inicio de la pubertad y aunque se haya reportado anteriormente que tratamientos exógenos con leptina recombinante para lograr este efecto han sido infructuosos (44), futuros usos terapéuticos con leptina recombinante que aborden diferentes estadios nutricionales y que tengan en cuenta la identificación de marcadores para genotipificación de la resistencia a la leptina deberían investigarse en el macho.

En conclusión, exite expresión de receptores de leptina en testículo de bovinos prepúberes y presentan la tendencia a aumentar mientras se acerca la pubertad. Esto podría indicar un posible rol de la leptina hacia la llegada de la pubertad. La regulación de la expresión de estos receptores está dada por un gran número de factores, entre ellos posiblemente, los niveles de testosterona circulantes, aunque harían falta estudios con mediciones periódicas de los receptores y de la hormona para verificar este supuesto. La expresión de 2 isoformas del gene de OBR hacia la llegada a la pubertad en bovinos sugiere una posible actividad conjunta y/o complementaria de estos 2 receptores para que la leptina desencadene sus efectos, pero se necesitan mayores estudios a nivel molecular y de vías de señalización para dilucidar este fenómeno.

\section{Agradecimientos}

A Colciencias-Colombia, proyecto 115-1216774, por la financiación del proyecto. A la ganadería Los Balcones y su propietario por el mantenimiento de los animales del experimento.

\section{REFERENCIAS}

1. Zhang $Y$, Proenca $R$, Maffei M, Barone M, Leopold L, Friedman JM. Positional cloning of the mouse obese gene and its human homologue. Nature 1994; 372:425-32.
2. Bartha T, Sayed-Ahmed A, Rudas P. Expression of leptin and its receptors in various tissues of ruminants. Domest Anim Endocrinol 2005; 29:193-202. 
3. Houseknecht $\mathrm{KL}$, Portocarrero CP. Leptin and its receptors: regulators of whole-body energy homeostasis. Domest Anim Endocrinol 1998; 15:457-75.

4. Barb CR, Hausman GJ, Houseknecht $\mathrm{KL}$. Biology of leptin in the pig. Domest Anim Endocrinol 2001; 21:297-317.

5. Tartaglia LA. The leptin receptor. J Biol Chem 1997; 272:6093-6.

6. Tartaglia LA, Dembski $M$, Weng $X$, Deng N, Culpepper J, Devos R, et al. Identification and expression cloning of a leptin receptor, OB-R. Cell 1995; 83:1263-71.

7. Schneider JE, Zhou D, Blum RM. Leptin and metabolic control of reproduction. Horm Behav 2000; 37:306-26.

8. Spicer LJ. Leptin: a possible metabolic signal affecting reproduction. Domest Anim Endocrinol 2001; 21:251-70.

9. Ruiz-Cortes ZT, Martel-Kennes Y, Gevry NY, Downey BR, Palin MF, Murphy BD. Biphasic effects of leptin in porcine granulosa cells. Biol Reprod 2003; 68:789-96.

10. Ruiz-Cortes ZT, Men T, Palin MF, Downey BR, Lacroix DA, Murphy BD. Porcine leptin receptor: molecular structure and expression in the ovary. Mol Reprod Dev 2000; 56:465-74.

11. Kawachi $\mathrm{H}$, Yang $\mathrm{SH}$, Hamano A, Matsui T, Smith SB, Yano H. Molecular cloning and expression of bovine (Bos taurus) leptin receptor isoform mRNAs. Comp Biochem Physiol B Biochem Mol Biol 2007; 148:167-73.

12. Williams GL, Amstalden M, Garcia MR, Stanko RL, Nizielski SE, Morrison CD, Keisler DH. Leptin and its role in the central regulation of reproduction in cattle. Domest Anim Endocrinol 2002; 23:339-49.
13. Barb CR, Kraeling RR. Role of leptin in the regulation of gonadotropin secretion in farm animals. Anim Reprod Sci 2004; 82-83:155-67.

14. Barb CR, Barrett JB, Kraeling RR, Rampacek GB. Serum leptin concentrations, luteinizing hormone and growth hormone secretion during feed and metabolic fuel restriction in the prepuberal gilt. Domest Anim Endocrinol 2001; 20:47-63.

15. Kaynard AH, Pau KY, Hess DL, Spies HG. Third-ventricular infusion of neuropeptide $Y$ suppresses luteinizing hormone secretion in ovariectomized rhesus macaques. Endocrinology 1990; 127:2437-44.

16. Kalra SP. Mandatory neuropeptidesteroid signaling for the preovulatory luteinizing hormone-releasing hormone discharge. Endocr Rev 1993; 14:507-38.

17. Malven PV, Haglof SA, Degroot $H$. Effects of intracerebral administration of neuropeptide-Y on secretion of luteinizing hormone in ovariectomized sheep. Brain Res Bull 1992; 28:871-5.

18. Horlick MB, Rosenbaum M, Nicolson $M$, Levine LS, Fedun B, Wang J, Pierson RN, Jr., Leibel RL. Effect of puberty on the relationship between circulating leptin and body composition. J Clin Endocrinol Metab 2000; 85:2509-18.

19. Qian H, Barb CR, Compton MM, Hausman GJ, Azain MJ, Kraeling RR, Baile CA. Leptin mRNA expression and serum leptin concentrations as influenced by age, weight, and estradiol in pigs. Domest Anim Endocrinol 1999; 16:135-43.

20. Cheung CC, Thornton JE, Kuijper JL, Weigle DS, Clifton DK, Steiner RA. Leptin is a metabolic gate for the onset of puberty in the female rat. Endocrinology 1997; 138:855-8. 
21. Garcia MR, Amstalden M, Williams SW, Stanko RL, Morrison CD, Keisler DH, Nizielski SE, Williams GL. Serum leptin and its adipose gene expression during pubertal development, the estrous cycle, and different seasons in cattle. J Anim Sci 2002; 80:2158-67.

22. Tena-Sempere M, Barreiro ML. Leptin in male reproduction: the testis paradigm. Mol Cell Endocrinol 2002; 188:9-13.

23. Tena-Sempere M, Manna PR, Zhang FP, Pinilla L, Gonzalez LC, Dieguez C, Huhtaniemi I, Aguilar E. Molecular mechanisms of leptin action in adult rat testis: potential targets for leptininduced inhibition of steroidogenesis and pattern of leptin receptor messenger ribonucleic acid expression. J Endocrinol $2001 ; 170: 413-23$.

24. Tena-Sempere M, Pinilla L, Gonzalez LC, Navarro J, Dieguez C, Casanueva $F F$, Aguilar E. In vitro pituitary and testicular effects of the leptin-related synthetic peptide leptin(116-130) amide involve actions both similar to and distinct from those of the native leptin molecule in the adult rat. Eur J Endocrinol 2000; 142:406-10.

25. Tena-Sempere M, Pinilla L, Gonzalez LC, Dieguez C, Casanueva FF, Aguilar E. Leptin inhibits testosterone secretion from adult rat testis in vitro. J Endocrinol 1999; 161:211-8.

26. Souza CE, Araujo AA, Oliveira JT, Lima Souza AC, Neiva JN, Moura AA. Reproductive development of Santa Ines rams during the first year of life: body and testis growth, testosterone concentrations, sperm parameters, age at puberty and seminal plasma proteins. Reprod Domest Anim 2010; 45:644-53.

27. Rawlings N, Evans AC, Chandolia RK, Bagu ET. Sexual maturation in the bull. Reprod Domest Anim 2008; 43 Suppl 2:295-301.
28. Price CA. Evidence that testosterone and follicular fluid do not interact in the control of FSH secretion in rams. Theriogenology 1994; 41:471-82.

29. Kadokawa $H$, Briegel JR, Blackberry MA, Blache D, Martin GB, Adams NR. Relationships between plasma concentrations of leptin and other metabolic hormones in $\mathrm{GH}$-transgenic sheep infused with glucose. Domest Anim Endocrinol 2003; 24:219-29.

30. Blache D, Tellam RL, Chagas LM, Blackberry MA, Vercoe PE, Martin GB. Level of nutrition affects leptin concentrations in plasma and cerebrospinal fluid in sheep. J Endocrinol 2000; 165:625-37.

31. Finnerty $M$, Enright $W J$, Roche JF. Testosterone, $\mathrm{LH}$ and FSH episodic secretory patterns in $\mathrm{GnRH}$-immunized bulls. J Reprod Fertil 1998; 114:85-94.

32. Aranguren-Méndez J, Madrid-Bury N, González-Stagnaro C, Isea Villasmil W. Evaluación comparativa postpuberal de toretes mestizos 5/8 Bos taurus. 2. Comportamiento Reproductivo. Arch Latinoam Prod Anim 1997; 5:347-49.

33. Lunstra DD, Ford JJ, Echternkamp SE. Puberty in beef bulls: hormone concentrations, growth, testicular development, sperm production and sexual aggressiveness in bulls of different breeds. J Anim Sci 1978; 46:1054-62.

34. Brito L, Barth A, Rawlings N, Wilde R, Crews D, Jr., Mir P, Kastelic J. Circulating metabolic hormones during the peripubertal period and their association with testicular development in bulls. Reprod Domest Anim 2007; 42:502-8.

35. Barnes MA, Longnecker JV, Charter RC, Riesen JW, Woody CO. Influence of unilateral castration and increased plane of nutrition on sexual development of Holstein bulls. I. Growth and sperm production. Theriogenology 1980a; 14:49-58. 
36. Barnes MA, Longnecker JV, Riesen JW, Woody CO. Influence of unilateral castration and increased plane of nutrition on sexual development of Holstein bulls. III. Endocrine responses. Theriogenology 1980b; 14:67-81.

37. Caprio M, Isidori AM, Carta AR, Moretti C, Dufau ML, Fabbri A. Expression of functional leptin receptors in rodent Leydig cells. Endocrinology 1999; 140:4939-47.

38. Tena-Sempere M, Pinilla L, Zhang FP, Gonzalez LC, Huhtaniemi I, Casanueva FF, Dieguez C, Aguilar E. Developmental and hormonal regulation of leptin receptor (Ob-R) messenger ribonucleic acid expression in rat testis. Biol Reprod $2001 ; 64: 634-43$.

39. Caprio M, Fabbrini E, Ricci G, Basciani S, Gnessi L, Arizzi M, Carta AR, De Martino MU, Isidori AM, Frajese GV, Fabbri A. Ontogenesis of leptin receptor in rat Leydig cells. Biol Reprod 2003; 68:1199-207.

40. Buff PR, Dodds AC, Morrison CD, Whitley NC, McFadin EL, Daniel JA, Djiane J, Keisler DH. Leptin in horses: tissue localization and relationship between peripheral concentrations of leptin and body condition. J Anim Sci 2002; 80:2942-8.
41. Jope T, Lammert A, Kratzsch J, Paasch $U$, Glander HJ. Leptin and leptin receptor in human seminal plasma and in human spermatozoa. Int J Androl 2003; 26:335-41.

42. Glander $\mathrm{HJ}$, Lammert $A$, Paasch $U$, Glasow A, Kratzsch J. Leptin exists in tubuli seminiferi and in seminal plasma. Andrologia 2002; 34:227-33.

43. Uotani S, Abe T, Yamaguchi Y. Leptin activates AMP-activated protein kinase in hepatic cells via a JAK2-dependent pathway. Biochem Biophys Res Commun 2006; 351:171-5.

44. Maciel MN, Zieba DA, Amstalden M, Keisler DH, Neves JP, Williams GL. Chronic administration of recombinant ovine leptin in growing beef heifers: effects on secretion of $\mathrm{LH}$, metabolic hormones, and timing of puberty. J Anim Sci 2004; 82:2930-6. 